\title{
ESPACIOS SAGRADOS ENTRE LOS MAYAS DEL LAGO ATITLÁN (GUATEMALA)
}

\author{
Perla Petrich \\ Universidad de París 8
}

Mi interés es analizar algunas de las múltiples construcciones y reconstrucciones de los espacios sagrados entre los mayas actuales con el propósito de poner de manifiesto su función social. Me concentré particularmente en uno de los pueblos del lago Atitlán en Guatemala (San Pedro de lengua tzutujil) y su tradición oral. Al no poder presentar en su integridad los relatos que utilizo como ejemplo, remito en nota a antologías en donde pueden encontrarse.

Antes de hacer referencia a un espacio sagrado o a la sacralidad espacial, creo necesario tomar algunas precauciones. Más allá de adjetivar o sustantivar un término, se trata de definirlo o, al menos, de establecer cuál es mi opción entre las múltiples definiciones posibles de lo sagrado.

Parto de la idea de que lo sagrado es una percepción mediatizada de los hombres con su origen. Una mediatización que consiste en evacuar la realidad para instalar y aceptar como autores de ese origen, la presencia de seres imaginarios, dobles de los hombres, pero con poderes superiores. ${ }^{1}$ Ese poder consiste en una fuerza energética estable o efímera, "anónima y difusa" — según la definición de Durkheim (1912) — que siempre es peligrosa, eficaz, incomprensible y con dificultad administrada. Una fuerza que provoca en el creyente, al mismo tiempo, deseo y temor. Una energía ambigua, potencialmente capaz de establecer el orden pero, según las circunstancias, también el desorden (Caillois, 1988). La ambigüedad sólo existe en el estado virtual porque, una vez manifestada, la certeza se impone. En tanto que fuerza actualizada su carácter es negativo o positivo, puro o impuro; santo o diabólico.... Los calificativos son múltiples para definir lo numinoso que aterroriza y, al mismo tiempo, fascina.

Varias son las preguntas acuciantes con respecto al tema de lo sagrado. La primera de ellas es ¿Para qué o por qué la existencia de lo sagrado? Posiblemente para legitimar un orden impuesto que permite la sobrevivencia de la sociedad; que asegura su producción y re-producción. Los relatos míticos, los ritos y las prácticas sagradas constituyen, o bien una cierta explicación, o bien una cierta puesta en escena del origen de las cosas cuya finalidad es "legitimar el orden

${ }^{1}$ Utilizo en este caso las ideas de base de Godelier (1998: 245), para quien lo sagrado es un cierto tipo de relación de los hombres con el origen de las cosas de una índole tal que en ella desaparecen los hombres reales y aparecen en su lugar dobles de sí mismos, hombres imaginarios. 
del universo y de la sociedad, al sustituir a los hombres reales que domesticaron las plantas y los animales, inventaron las herramientas y las armas, etc., por hombres imaginarios que no lo hicieron pero recibieron esos favores de manos de los dioses o de héroes fundadores" (Godelier, 1998: 246).

Concretamente "el orden de la sociedad" se traduce por relaciones establecidas entre los miembros de la sociedad. Relaciones entre los que dominan y los que deben obedecer para subsistir. A los que dirigen les conviene que su poder se perpetúe con el consentimiento del resto de la sociedad. Lo sagrado se inserta en esa situación para "legitimar" el orden social establecido.

Otra de las preguntas ineludible es ¿En dónde se origina la fuerza sagrada? Se perfilan en Francia dos líneas explicativas: una sociológica representada por Emile Durkheim y otra antropológica propuesta por Claude Lévi-Strauss y Maurice Godelier.

Para Durkheim (1912) lo sagrado resulta de una fuerza provocada por la sociedad misma; la sociedad en tanto que autoridad moral susceptible de despertar veneración. Desde este punto de vista, la sociedad se transfigura en objeto de culto, se convierte en un ideal colectivo, suscita "la comunión de conciencias" y provoca el sentimiento de pertenencia a un mismo grupo.

Frente a este dominio de la afectividad, Lévi-Strauss (1950) propone la esfera de lo sagrado como una concepción del pensamiento, como un sistema simbólico que expresa relaciones abstractas y es el resultado, no de operaciones emocionales, sino de un mecanismo racional de comprensión de los hechos sociales.

Por su parte Godelier (1998) plantea lo sagrado como una consecuencia de las relaciones sociales. Se supone entonces que la sociedad para instaurarse, persistir y reproducirse, necesita justificar a través de un proceso de sacralización sus orígenes y su organización de clases sociales, modos de dominación, costumbres... La sociedad proyecta sus propias leyes sobre objetos, animales, fenómenos naturales y seres fantásticos. Todos ellos presentan y, al mismo tiempo, disimulan el contenido de las relaciones sociales. Las leyes están idealizadas, transmutadas, sacralizadas, de tal manera que no puedan ser contestadas y se conviertan en bien común.

Podríamos resumir las perspectivas antropológicas diciendo que lo sagrado se considera en el primer caso como producto de una mecánica intelectual cuya explicación y sentido se encuentra en su propia lógica simbólica inmanente; en el segundo, como una estrategia social a través de la cual se evita la contestación y se provoca el asentimiento a un orden. En este caso lo sagrado establece una relación de los hombres con el origen de lo existente. Una relación que se caracteriza por la opacidad (Godelier, 1998: 241), por la ocultación de lo real. Ese proceso de ocultación consiste en erradicar al hombre de su propio origen y del origen y la organización de todo lo existente. De este modo se lo coloca en situación de producto del deseo o del capricho de poderes superiores que decidieron su creación y su modo de vida. Los hombres son afortunados receptores; 
no han inventado ni creado nada. En consecuencia, son permanentes deudores de las fuerzas sobrenaturales y de ellas emanan las reglas de vida.

La perspectiva de Lévi-Strauss es otra: el objeto, el ser sobrenatural, el animal, el lugar específico, son considerados en tanto que símbolos puros; símbolos de un poder superior. Desde una perspectiva, si no complementaria, al menos amplificadora, Godelier considera que esos símbolos no remiten a un significado que hace abstracción de lo social, sino que presentan, al mismo tiempo que disimulan, el contenido de las relaciones sociales (Godelier, 1998: 243). En este sentido, lo inconsciente sirve como instrumento o medio para expresar lo sagrado, pero no como origen, tal como lo supone Lévi-Strauss.

Si se afirma que los objetos, los seres, los lugares símbólicos encubren lo social es porque se imponen como desprendidos de toda contingencia humana, originados ex-nihilo, o productos de potencias superiores. Sin embargo, tal como lo propone Godelier, materializan, sintetizan visiblemente, no sólo lo que la sociedad quiere presentar, sino también lo que quiere disimular de sí misma. De ahí que este autor concluya estableciendo que las representaciones de lo sagrado unifican en sí mismas el contenido simbólico, imaginario y real de las relaciones sociales (Godelier, 1998: 243).

En mi caso, es la teoría de Godelier la que más se ajusta conceptual y metodológicamente para un análisis del espacio sagrado maya. En las páginas siguientes abordo el tema en gran parte desde su perspectiva.

\section{El espacio: propiedad de las divinidades}

La totalidad del espacio maya, por ser propiedad de las divinidades, es considerado sagrado, por lo tanto, permanentemente y bajo distintas formas, el hombre está pactando con ellas su derecho de instalación y desplazamiento. Derecho a cultivar una milpa, a cazar en el monte, a construir la casa en un terreno, a caminar por las calles del pueblo o senderos de la montaña. La relación entre hombre-espacio-divinidad(es) es una constante pero inscrita en el tiempo, en consecuencia, sujeta a las variaciones históricas y geográficas.

Hablar del espacio sagrado entre los mayas nos plantea como punto de partida un problema fundamental: ¿Podemos utilizar en este caso la categoría clásica de Durkheim y definir "lo sagrado" como uno de los términos del binomio "sagrado-profano" y establecer así una neta separación entre lo profano-cotidiano (frente a lo cual no se necesita ninguna precaución) y el otro mundo sagrado sujeto a normas y ritos?

En el mundo maya esta bipolaridad no parecería existir: todos los espacios son receptáculos posibles para recibir fuerzas sagradas. Esta potencialidad de lo sagrado es la que somete la totalidad de las prácticas a códigos estrictos de conducta. En este sentido la sacralidad asegura que nada quede al azar. Cada acción efectuada en el espacio, sea cual sea, debe llevarse a cabo de una manera deter- 
minada para provocar o evitar las fuerzas sagradas. La milpa se trabaja con machete y con azadón, pero también con plegarias y con incienso. El campo de cultivo, al menos tradicionalmente, nunca tuvo un valor puramente agrícola. Siempre estuvo, en mayor o menos medida según los períodos de labranza, sacralizado.

Todos los espacios, aun los banales, tienen una potencialidad sagrada. Una calle cualquiera puede imprevistamente transformarse ante la aparición de uno de los tantos personajes terroríficos que existen en el imaginario maya. Si se trata del mediodía o la noche, no es conveniente aventurarse para evitar así el daño que puede provocar el encuentro con un characotel. ${ }^{2}$ Ése y muchos otros animales imaginarios representan, no sólo el poder negativo de una fuerza sobrenatural, sino también una forma desdoblada de aplicación de reglas colectivas y el castigo que merece quien no las respeta.

Cada espacio asociado a un ser imaginario es un espacio controlado y cada espacio controlado limita la acción y la elección de prácticas de los individuos. Las normas suelen ser similares en el caso de la mayoría de las sociedades tradicionales, sean o no mayas: es necesario acostarse a determinada hora para comenzar a trabajar al alba; no caer en la borrachera y evitar los encuentros adúlteros. La particularidad de cada sociedad se encuentra en las formas que imaginan para hacer cumplir esas normas, por ejemplo, en la tradición oral creada en relación con los espacios en donde esas normas se actualizan, ya sea cumpliéndolas o transgrediéndolas.

Los lugares nocturnos que escapan a la posibilidad de una vigilancia constante propician las transgresiones. Para asegurarse que los hombres se recojan a una hora temprana y no beban, se escuchan continuamente en San Pedro relatos referidos a los characoteles o a La Llorona. Las versiones son múltiples, pero a grandes rasgos se resumen en historias de hombres que vuelven de la cantina tarde en la noche. En caminos no centrales, en senderos alejados, en los barrancos, se encuentran con animales peligrosos que los atacan o una mujer de largos cabellos que intenta seducirlos para provocarles la muerte. ${ }^{3}$

Con respecto a las relaciones adúlteras, es frecuente escuchar relatos sobre La Ronda, un viento "vigilante" que pasa y arrasa con todo lo que encuentra en su camino. Múltiples relatos cuentan de parejas sorprendidas por este "aire" en las playas del lago y encontradas muertas al día siguiente.

La sacralidad que se proyecta en el espacio poblado por seres imaginarios "disimula" lo que la sociedad dice e impone. De esta forma "metamorfoseadas", las leyes mantienen su vigencia y, en mayor o menor medida, se respetan. En otras palabras, los relatos legitiman el orden establecido porque éste no parece

\footnotetext{
${ }^{2}$ Personas que se transforman de noche en un animal o toman el aspecto de otra persona para provocar daños a los vecinos..

${ }^{3}$ Múltiples relatos sobre estos temas se encuentran en Ochoa (1999).
} 
estipulado, ni castigado su incumplimiento, por los hombres que poseen el poder, sino por seres imaginarios, superiores, que no pertenecen al ámbito humano. El hombre se somete o transgrede. Los relatos de la tradición oral cuentan sobre los resultados de una actitud u otra. Pero, como ya lo hemos señalado, no se limitan a las consecuencias; su función es además la de establecer las condiciones, es decir, fijar las "reglas del juego", el marco en el que el hombre debe desplazarse y las formas de prevenir los peligros. $Y$ es en este punto en donde interviene la "opacidad" de lo social como consecuencia de la sacralización (Godelier, 1998: 242): las "reales" relaciones (de dominación de unos por otros, de control político, económico....) se metamorfosean, se ocultan tras esos seres imaginarios (La Llorona, los characoteles, el Cadejo, los Ancestros, las Ánimas....) que proponen la aceptación, el consentimiento, la obediencia, la continuidad de lo que ha sido establecido desde siempre.

El relato establece condiciones indispensables para la existencia; persuade a través de una violencia velada; una coerción que no parece real porque está proyectada en la ficción y en seres idealizados. En definitiva, y parafraseando a Godelier, si para una parte de la sociedad — la que gobierna_ las relaciones sociales existentes son consideradas convenientes, es necesario que lo sean también para el resto de la sociedad. Todos deben aceptar que el orden establecido es el mejor y el más seguro.

Los relatos en su conjunto crean una geografía sagrada que oficia de administración social, es decir, coarta pero, al mismo tiempo, protege, ya que el trazado de límites territoriales "permitidos" y "prohibidos" permite al individuo moverse en un espacio seguro. Basta con no aventurarse por lugares solitarios, con no bajar a los barrancos, con no entrar a las cuevas... para evitar el peligro. ${ }^{4} \mathrm{El} \mathrm{hom-}$ bre en este caso vive lo sagrado - la ley - con temor pero, al mismo tiempo, con confianza, ya que lo confronta simultáneamente al peligro y a la forma de evitarlo. Reacción que inevitablemente se logra con lo que Godelier (1998: 248) define como el consentimiento de todos frente a las normas. Consentimiento que garantiza la organización y la reproducción de la sociedad. La repetición de múltiples versiones de historias en donde se "comprueba" que los hombres de noche son atacados por las fuerzas del mal o que en las orillas del lago abundan aires nocivos como "La Ronda" o las Ánimas de los muertos que se reúnen para determinar quién será en el pueblo el próximo en morir, se convierte en un argumento irrefutable para evitar esos lugares. La única condición para mantener vigentes las normas es que se crea en la verdad de las historias. Cuando los niños se escolarizan o los pobladores emigran en busca de trabajo y de otros horizontes culturales y el pueblo se abre al turismo y a un sistema mundialista de existencia que los asemeja de más en más a "los otros", el valor sagrado de espacios y seres imaginarios se debilita e incluso desaparece.

${ }^{4}$ Para mayor información sobre el espacio nocturno, consultar Petrich (2003). 


\section{Variedad de espacios sagrados en los pueblos del lago}

La geografía sagrada se establece a partir de un determinado reparto de fuerzas en los distintos espacios y de sus diferentes modalidades de aparición o permanencia.

Existen espacios que en forma permanente acogen fuerzas sagradas, espacios consolidados a los que, apoyándonos en Florence Brunois, podríamos definir como "espacios de memoria" (una roca, un árbol determinado en tal lugar, las cruces del pueblo, los barrancos, las grutas, los altares construidos en la montaña, la iglesia...). Algunos de estos espacios se caracterizan por concentrar fuerzas negativas unívocas (los barrancos) o positivas (la iglesia del pueblo). Sin embargo, existen también espacios fluctuantes en donde, al mismo tiempo, la eventualidad de una fuerza u otra es posible, según quién oficie los ritos. En los altares de las montañas o en las grutas pueden ir a hacer sus "parlamentos" tanto los brujos como los buenos curanderos. En San Pedro cuentan que muchas personas obtuvieron favores (dinero, curación, aceptación de una persona amada...) porque en tal o tal altar de la montaña hicieron ofrendas y rezaron junto con un curandero. También cuentan que algunos pobladores hicieron fortuna porque con "un brujo" la pidieron en un altar al Dueño del volcán San Pedro.

El resto del espacio público y privado sería definido como espacios de vivencias sagradas esporádicas. En este caso existe latente la ambiguiedad: si un hombre encuentra sobre un matorral la estatua de un santo, ese espacio queda inmediatamente sacralizado positivamente. Por el contrario, el espacio se sacraliza como impuro si en el camino se encuentra con el Sombrerón o un characotel.

La casa es el espacio más importante de vivencias sagradas esporádicas. Allí se llevan a cabo la mayoría de las prácticas cotidianas (se cocina, duerme, juega, limpia, teje) pero también se reza en momentos especiales y se llevan a cabo ritos domésticos, propiciatorios o de expiación. Desde el momento en que un lugar (ya se trate de un espacio o un utensilio) es utilizado con otra finalidad que la puramente práctica y utilitaria, la fuerza sagrada se instala. Así ocurre con el rincón en donde el dueño de la casa enciende una vela y pronuncia un rezo ante una estampa de la Virgen para conjurar una epidemia que le anunciaron sus gallinas cantando en demasía al anochecer o en la troje de la cocina, de donde se extraen mazorcas agradeciendo a la divinidad con "buenas palabras", o en el fogón, en donde la mujer quema granos de pimienta para anular "el mal de ojo" que atacó a uno de los niños, o en el fondo de la gran olla de barro, en donde la novia despechada mete la cabeza para llamar al hombre que la dejó.

Una excepción es la casa del curandero o el brujo, porque ese espacio goza a la vez de carácter fijo y móvil de sacralidad. Fijo: la habitación o el rincón en donde tiene instalado su altar con estampas, piedras para adivinar y generalmen- 
te la figura de Maximón, ${ }^{5}$ y móvil, por ejemplo, el huerto en donde, por lo general, corren los niños, se plantan o recogen hortalizas, se teje en el telar atado al árbol más cercano. Esa cotidianidad cambia cuando allí se lleva a cabo el sacrificio de un gallo o una gallina o se quema copal.

La sacralidad esporádica también suele concentrarse en un espacio sonoro extendido y casi ilimitado creado por el aullido de perros o el graznido de ciertos pájaros que tienen valor de presagio; también en espacios coloreados, como puede ser el efímero del arco iris, que se supone provocado por el aliento de una serpiente gigantesca que vive detrás del volcán Atitlán.

El cuerpo es uno de los espacios privilegiados para incorporar fuerzas sagradas. También en este caso la ambiguiedad es una característica frecuente: un cadáver se considera un espacio sagrado impuro. Una vez enterrado puede convertirse en un protector venerado o en un ánima destructora. Se sueña con él con alivio o con temor. A su vez, el cuerpo de los vivos funciona como receptáculo de fuerzas sagradas: el tranquilo agricultor de noche, dando tres saltos hacia atrás puede metamorfosearse en animal, y como characotel, ser portador de fuerzas negativas.

No podemos dejar de lado el espacio onírico, espacio sagrado en su totalidad. Espacio sin contornos precisos. Allí se producen encuentros y diálogos con las divinidades, con los ancestros, con el ánima de los muertos, y eso sin requisitos previos, ni ritos propiciatorios o protectores, ni tampoco intermediarios. Desaparecen todos los límites que en el mundo diurno son estrictos y están sujetos a prohibiciones: el alma puede pasar al mundo de los muertos y encontrarse con sus antepasados o familiares muertos, puede ir al mundo subterráneo o volar. Espacio socializado a través del relato. El relato del que ha soñado y cuenta y el relato del padre, el abuelo o el curandero que lo interpreta. Es el relato interpretativo el que convierte al sueño en un hecho comprensible y socialmente útil. El espacio del sueño se hace entonces analógico al espacio real y cobra sentido, es decir, se encuadra en el orden preexistente: si se soñó que el abuelo aparecía y miraba a los hijos con cara enojada, eso "significa”, según el curandero, que es necesario no olvidar festejar con las ceremonias estipuladas los aniversarios de su muerte o que piensa castigar a algún miembro de la familia porque no se ha comportado correctamente con los vecinos o con un hermano. Los ancestros ocupan el espacio del sueño para "administrar a los vivos, para hacer cumplir con el orden establecido. La interpretación del curandero hace comprensible el contenido del sueño y, gracias al conocimiento que tiene de las "transgresiones" del que sueña o de su familia, lo convierte en instrumento de control. Podría postularse hipotéticamente que el sueño es socialmente inducido en el individuo y que, a través de la interpretación, se previenen las faltas o se las castiga.

\footnotetext{
${ }^{5}$ Una máscara con cuerpo de trapos adorada como una divinidad que en su origen fue creada para vigilar a las mujeres mientras sus maridos trabajaban pero a la que hoy se le pide todo tipo de servicios.
} 
Si se proyecta a la tradición oral la distinción entre "espacios sagrados de memoria" y "espacios sagrados de vivencias esporádicas", constatamos que, con respecto a los espacios sagrados de memoria, se elabora un tipo de relato perfectamente estructurado, de carácter mítico. Por ejemplo, los relatos sobre la ocupación del territorio, es decir, la aparición de los santos y la construcción de la iglesia o la existencia de los Dueños o del maíz en el interior de las montañas... En el caso de los espacios sagrados de vivencias, nos limitamos a relatos recientes, testimoniales y generalmente referidos a la propia experiencia o a la del vecino. Intervienen en este caso personajes como el Cadejo, La Llorona, los characoteles, los relatos de vida. La localización es mucho más indeterminada ${ }^{6}$ e imprevisible: las apariciones se producen en un recodo del camino, detrás de una maleza, al lado de un árbol, detrás o delante de una roca en el fondo del barranco...). Nos encontramos en este segundo caso con lo que Bastide (1975: 234) define como "sagrado salvaje", un sagrado "difuso" y, en consecuencia, desmesurado e incontrolable. Ese sagrado que no llegó nunca a institucionalizarse como religión y perduró incontrolable y situado en el nivel de lo imaginario y no de la memoria (Bastide, 1975: 215).

Los relatos, situados en ese nivel de "sagrado salvaje", reproducen la transgresión (dejarse seducir en senderos alejados por una hermosa mujer; entrar a la cueva de la montaña en busca de riquezas, andar solo de noche por los caminos...) y, al mismo tiempo, la circunscriben espacialmente y de ese modo la exorcizan.

Las clasificaciones que he establecido anteriormente son operantes pero no hay que olvidar que, como todo fenómeno social, la representación de los espacios sagrados sufre modificaciones. Los espacios siguen perteneciendo a las divinidades, pero las argumentaciones para su ocupación o su abandono varían, porque han variado las relaciones sociales, ya que los grupos están ahora sometidos a otras exigencias económicas o a otras influencias culturales.

Antes se purificaba la casa para evitar la presencia de los malos espíritus; hoy se "limpian" ritualmente las tiendas de computadoras o los campos de marihuana. Antes la gente tenía accidentes en el lago o en el monte. El espacio de esa muerte inmediatamente se convertía en peligroso porque el alma del difunto quedaba allí aunque se hubieran llevado el cuerpo a la casa. El "buscador de almas" venía a recogerla a ese lugar y se la llevaba hasta depositarla en el cuerpo del herido. Los accidentes hoy en día suelen producirse en espacios diferentes, como puede ser una carretera de gran tráfico. Hace unos años un autobús que iba de San Pedro La Laguna a Panajachel en la zona del lago Atitlán, chocó y hubo muertos y más de treinta heridos, todos hospitalizados y luego llevados a sus casas. El buscador de almas tuvo que hacer treinta viajes

\footnotetext{
${ }^{6}$ Véase sobre este punto una perspectiva general planteada por Roger Caillois (1988: 69).
} 
hacia el lugar en donde se produjo el accidente y realizar el ceremonial de traída del alma entre las bocinas de los autos y el paso ensordecedor de los camiones. Nada, visto desde el exterior, podía hacer suponer que ese lugar estuviera sacralizado porque treinta almas lo habitaban.

Antes, en San Pedro, se suponía que los malos espíritus se apropiaban de las calles a partir de las ocho de la noche, hoy como la mayoría de los pobladores son adeptos a las telenovelas que terminan a las nueve de la noche y les gusta dar un paseo antes de acostarse, el horario "sagrado" se ha desplazado y se supone que los characoteles no aparecen antes de las diez de la noche.

Muchos pobladores de San Pedro dicen que antes se escuchaban los lamentos de La Llorona en las calles del pueblo; hoy aseguran que ya no se oyen sino en las afueras. Hoy en día la gente ya no tiene miedo de aventurarse en el monte porque los lugares "peligrosos" se han limitado con la extensión de los cultivos. Sólo quedan algunos barrancos y pocos lugares, todos perfectamente delimitados (el interior de los volcanes, el fondo del lago Atitlán, por ejemplo), en donde se considera que aparecen Ánimas o personajes malignos.

Lo que se opera con el paso del tiempo y la entrada en la modernidad es lo que Bastide (1975) definió como "una domesticación" de lo sagrado, una especie de recuperación racional y casi burocrática del "sagrado salvaje" al que ya anteriormente hice referencia. Ese sagrado "salvaje" que depende en parte de la experiencia de cada uno, que es creación pura y no repetición, va desapareciendo a medida que los pueblos se modernizan. Actualmente el paisaje suele mirarse como un entorno objetivo y objetivado. Ya no estamos en el marco del signo - todo se lee como significante- sino de la funcionalidad: las tierras sirven para cultivar el producto más rentable, el pueblo para instalarse y vivir. El paisaje que antes se leía buscando indicios de sacralidad (el color de la nube, la forma de una roca, un árbol gigantesco, un barranco, una gruta...), suele reducirse a una valorización puramente productiva.

Otros cambios se producen, no por la vía económica o política, sino religiosa. Las Iglesias protestantes cada vez más presentes, crean nuevas gestiones de los espacios sagrados. Podríamos referirnos más bien a transferencias de lo sagrado hacia nuevos espacios, por ejemplo hacia algunos bares para turistas en el lago Atitlán, iluminados sólo con velas, en donde por lo general se fuma marihuana, se escucha música estridente y se bebe alcohol. Contra ellos las Iglesias protestantes esgrimen un vocabulario apocalíptico: "lugares de condenación eterna", "antros de pecado mortal", etc. Y en torno a ellos surge una nueva tradición oral en donde se relata "la perdición" de jóvenes que vivían felices y protegidos por la familia y terminan como vagabundos y viviendo con los hippies extranjeros, los que en el caso de San Pedro, radican en un barrio relativamente alejado del centro y son mirados con desprecio por los pobladores tzutujiles. 


\section{Límites y contactos entre lo sagrado "puro" y lo sagrado "impuro"}

La sociedad necesita almacenar fuerzas para protegerse. Su existencia y supervivencia dependen del poder que tenga de usar las fuerzas superiores y de convertirlas en positivas. Mientras mayor es la fuerza, mayor se supone que es su eficacia (Caillois, 1988: 58). De ahí la tentación permanente de cambiar lo negativo-impuro en instrumento de purificación.

El interior de las montañas en donde vive el Dueño es un espacio que en el imaginario se reviste de fuerzas ambiguas: en un sentido, lugar de la divinidad que castiga e impone trabajos forzados si no se le pidió permiso debidamente para cazar o pescar y, en otro, lugar de la divinidad que otorga riquezas (oro y piedras preciosas). La tradición oral abunda en relatos en donde esta ambiguiedad está presente: el hombre rechaza aterrorizado este lugar y, al mismo tiempo, se siente fascinado por penetrar y apropiarse de lo que ahí existe. Muchas historias hablan de un hombre que entra en la montaña y logra resistir a los duros trabajos impuestos por el Dueño. Después de muchos años, al salir recibe como recompensa una caja de tesoros, eso implica metafóricamente la reversibilidad de las fuerzas negativas en fuerzas positivas; el triunfo de la luz sobre las tinieblas. Sin embargo la aventura por lo general es de corta duración: los relatos dicen que el hombre reparte las riquezas entre los pobladores o hace construir una iglesia pero al poco tiempo muere. ${ }^{7}$ El contacto con fuerzas sagradas excesivamente poderosas aniquila al hombre común. En este sentido es interesante destacar que hay muchos relatos que cuentan de personas que se enriquecieron porque entraron en el interior de la montaña acompañadas de "un brujo" que les ayudó a extraer el tesoro. En esos casos, gracias a la utilización de un intermediario capaz de pactar con lo sobrenatural, el relato no termina con la muerte del protagonista.

Con respecto a los muertos, es interesante constatar que existen espacios de reversibilidad posible de lo negativo a lo positivo y otros en donde el límite es infranqueable. En el caso de reversibilidad, observamos que el cadáver y todos los objetos que le pertenecieron, como así la habitación en donde yace, están contaminados de impureza, de fuerzas negativas. El cementerio, en el momento del entierro, es un espacio peligroso, nadie debe tocar la tierra de ese lugar ni tardarse allí mucho tiempo. Respetados todos los ritos que impone la muerte, al final del duelo, la casa deja de ser portadora de fuerzas negativas, el muerto adquiere el valor de ancestro venerado, sus objetos se conservan como reliquias y se acepta su aparición con placer en el espacio del sueño porque aconseja o dice palabras premonitorias. Incluso se recibe su alma una vez al año, el día de los muertos, en el cementerio, espacio que a su vez se ha purificado, a condición de que se respete un horario diurno, al punto de que es posible entonces consumir allí alimentos y compartirlos con el difunto.

\footnotetext{
${ }^{7}$ Para mayor información sobre este tipo de relato consultar Petrich (1998: 32).
} 
Sin embargo, al cementerio "vienen" los difuntos de "visita", para acercarse a los vivos, pero su lugar de residencia es otro: un mundo subterráneo que en el caso de los pueblos del lago se localiza en el fondo del lago. Los muertos no deben permanecer en el espacio de los vivos, sólo tienen derecho a apariciones esporádicas, y los vivos que llegan a conocer el mundo de los muertos, aun cuando logren regresar, no tardan en morir. ${ }^{8}$

Lo anterior implica entonces la posibilidad de que ciertas fuerzas negativas puedan ser revertidas y su energía aprovechada positivamente (el caso de ciertos espacios asociados a los muertos), mientras que otras, principalmente las localizadas en lugares fijos, lugares de memoria (el espacio subterráneo de los muertos, el espacio de los dueños de la montaña, "el infierno" en ciertos grupos mayas más permeables al imaginario católico...) sean irreversibles. El contacto entre los dos mundos es tabú. De este modo se protege el orden del mundo de los vivos y se evita el exceso, la desmedida.

Las separaciones o las comunicaciones espaciales que se representan en el plano sagrado tienen una relación directa con el espacio social real: los ancestros considerados "los verdaderos propietarios de las cosas y de los bienes del mundo" (Mauss, 1950: 167), deben controlar a sus deudos para que hagan una buena administración de lo que les han legado (bienes materiales pero también bienes culturales y sociales, como pueden ser ciertos comportamientos que involucran el respeto a los mayores, a las autoridades, etc.) so pena de desposeerlos. De ahí que puedan "aparecerse" en este mundo de tiempo en tiempo o en fechas fijas como el "Día de los muertos" para probar su existencia y, en consecuencia, su actualidad "vigilante". Pero es imposible que permanezcan en este mundo porque su poder se origina y alimenta en el otro espacio, un "más allá" definitivamente consagrado. A su vez, si el hombre lograra circular en el "más allá", eso significaría que es tan poderoso como las divinidades o los ancestros y esto desequilibraría todas las jerarquías sobre las que se asienta la organización social. De ahí que en la mayoría de los relatos se los destine a morir después de haber conocido el otro mundo.

\section{Para concluir}

La base de las demarcaciones espaciales se encuentra, ya sea en el asentamiento, ya sea en el desplazamiento de fuerzas sagradas. Estas limitaciones imaginarias tienen una incidencia directa en la cotidianidad y, en gran medida, controlan la vida del grupo. Por una parte, inhiben y suelen dar lugar a reacciones transgresoras pero, por otra, otorgan seguridad provocando consensualmente la aceptación. El hombre confinado en el espacio permitido, es decir: obedeciendo las normas, se protege del peligro, puede proyectarse hacia el futuro.

\footnotetext{
${ }^{8}$ Para mayor información, véase Petrich (2003 bis).
} 
Lo anterior no quiere decir que el espacio esté circunscrito en forma fija y definitiva. La movilidad adjudicada a las fuerzas sagradas es lo que asegura una dinámica permanente: ciertos espacios reducen su sacralidad en determinado momento; otros se desacralizan para resacralizarse en otras condiciones; nuevos espacios sagrados se instauran y determinan actitudes hasta ese momento desusadas..., las estrategias creativas son variadas y dependen de la aparición de agentes o situaciones nuevas. En definitiva: las fuerzas sagradas son tan dinámicas como las sociedades en donde circulan, y como ellas, deben adaptarse a los avatares de la modernidad para seguir siendo operantes.

\section{BIBLIOGRAFÍA}

Bastide, Roger

1975 Le sacré sauvage et autres essais. París: Payot.

Brunois, Florence

en prensa "Une re-lecture du paysage sacré Kasua (Province du Sud de la Papouasie-Nouvelle Guinée)" (por publicarse en Sites sacrés naturels. Diversité culturelle et diversité biologique. Actes du Symposium International UNESCO/ CNRS/MNHN, 1998 (22-25 septiembre)].

Caillois, Roger

1988 [1942] L'homme et le sacré. París: Gallimard.

Durkheim, Emile 2003 [1912] Les formes eléméntaires de la vie religieuse. Francia: PUF.

Godelier, Maurice

1998 El enigma del don. Barcelona: Paidós.

Mauss, Marcel

1950 Sociologie et anthropologie. París: PUF.

Lévi-Strauss, Claude

1950 "Introduction à l'œuvre de Mauss", Sociologie et anthropologie, pp. 9-52, París: PUF.

Petrich, Perla

1993 "Les contentieux de la mémoire”, Mémoire de la tradition, pp. 162- 187, A. Becquelin y A. Molinié (éd.), París: Université de Nanterre, Société d'Ethnologie.

(ed.)

1998 Literatura oral de los pueblos del lago Atitlán. Guatemala: CAEL-MUNIKAT. 
Petrich, Perla (ed.)

1998b Pueblos y santos del lago Atilán. Guatemala: CAEL-MUNIKAT.

2003 “Topología nocturna en los pueblos mayas de Atitlán”, Espacios mayas: representación, usos y creencias, pp. 577-601, A. Becquelin, A. Breton y M. Ruz (eds.). México: UNAM, IIFL, Centro de Estudios Mayas-Centro Francés de Estudios Mexicanos y Centroamericanos.

2003b "La muerte a través de la tradición oral maya", Antropología de la eternidad. La muerte en la cultura maya, pp. 473 - 501, Andrés Ciudad Ruiz, Mario Humberto Ruz Sosa, $\mathrm{M}^{\mathrm{a}}$ Josefa Iglesias y Ponce de León (eds.). Madrid: Sociedad Española de Estudios Mayas-Centro de Estudios Mayas, Madrid (Publicaciones de la SEEM, 7).

Petrich, Perla y Carlos Ochoa García (eds.)

2001 Cuentos del lago. Guatemala: Cholsamaj.

Ochoa García, Carlos

1999 Historias de la noche del lago Atitlán. Guatemala: CAEL-MUNIKAT. 